\title{
Improving the Ability of Mathematics (Conceptual and Procedural) Through Mathematical Investigation on Prospective Elementary Teachers
}

\author{
Nana Sumarna \\ Halu Oleo University \\ Indonesia
}

\author{
Wahyudin \\ Indonesia University of Education \\ Indonesia
}

\author{
Tatang Herman \\ Indonesia University of Education \\ Indonesia
}

\begin{abstract}
This study aims to determine the increase in the ability of conceptual and procedural on prospective elementary teachers, through a learning experiment with a mathematical investigation approach. The results showed that (1) there is an increased ability to conceptual and procedural abilities which was significant at all the students who get teaching investigation of mathematics, (2) in terms of prior knowledge mathematics, high and medium group showed a significant increase in understanding, otherwise the low group gave different results and (3) there is no interaction between the learning undertaken factor (mathematical investigation and expository) with prior knowledge of mathematics to increase the ability of conceptual and procedural abilities.
\end{abstract}

Keywords-Mathematical Investigation; conceptual; procedural; prospective elementary teachers

\section{INTRODUCTION}

Several studies on the prospective teacher shows that mathematical skills are less likely to provide optimal results. They are unable to see the reasonablenessof their answers and so are unable to monitor their own use of procedures. There is evidencethat prospective teachers have a similar reliance on formulae and procedures in the topic of area ([1]; [2]). Similarly, research has shown thatprospective teachers rely on procedures in other areas of mathematics, such as functions[3] and division [4]. The accepted importance ofsubject knowledge would suggest that a teacher, with limited understanding of the mathematical concepts, would not be effective in developing children's understanding for a topic.Studies, such as [5], have found that many prospective teachers represented the topic of area through the demonstration of procedures and the use of formulae,rather than focusing on activities that would support understanding. What we do not knowiswhether these were the prospective teachers who, themselves, had limited understanding. With their investigation of preservice elementary teachers' understanding of mathematics and its teaching, [6] reported that the mathematical understanding of preservice teachers in the United Kingdom was strongly embedded in preservice teachers' accounts of their own mathematical experiences, where mathematics was perceived as difficult and threatening.

The condition is clearly provide information that prospective elementary teacher math skills as an issue that should receive serious attention, given the importance of their roles and responsibilities in time become an elementary school teacher. Mathematical ability is basically composed of the ability of conceptual and procedural. To reach an understanding of mathematics, students must have a balance between the ability of conceptual understanding and mathematical procedures. However, there is controversy as to how much relative emphasis should be placed on procedural and conceptual knowledge no matter what the course level. Procedural knowledge is no guarantee of any gain in conceptual knowledge, even though there is evidence to support that procedural knowledge can precede conceptual knowledge. Indicated that conceptual knowledge is critical for students to advance in mathematics, and that learning new concepts depend on concepts that students have learned previously. Several research suggests that the ability of conceptual understanding is an aspect that is very important for a student, especially in problem solving. For example, Conceptual knowledge has been shown to help people evaluate which procedure is appropriate in a given situation (e.g., [7]; [8]), Conceptual knowledge also allows for more flexible problem solving, in that people who understand the conceptual underpinnings of a procedure are more likelyto successfully generalize it to novel problems [9]

Context of the development of this mathematical abilities, both conceptual and procedural understanding, can't be separated from the learning process conducted by a lecturer in learning of mathematics. The process should be oriented towards learning, with emphasis on activities that stimulate the development of students' abilities. Students should be actively involved in the process of meaningful mathematics, discussing mathematical ideas, and apply mathematics in a situation that 
is interesting and challenging ideas. The ability of students to these two types of abilities, will grow through a reflection and confronted with a challenging cognitive task.

One approach to learning that fits the above description is a mathematical investigation. This approach is based on the activity and is a combination of problem solving and problem posing. Through the study of mathematics by investigative approach, students learn and develop the knowledge and ability of mathematical processes through an integrated investigative activities in mathematics. Learning math like this will load the investigation activity, investigation task, investigation work or investigation process, also covers aspects of problem solving, filing problem, inductive reasoning and heuristic or mathematical thought process. Learning math with an investigative approach forms of indirect learning approaches (indirect approach), characterized by inductively. Increased student understanding of mathematical skills in the context of mathematical investigation caused by the investigation as an activity and as an investigation process. Explains that when students tried to open investigative tasks, they are engaged in mathematics called open investigative activities [10]. Therefore, this research is to apply the mathematical investigationapproach in learning geometry on the prospective elementary teacher.

\section{A. Conceptual understanding}

Some literature suggests that the definition of conceptual abilities. [11] stated that knowledge that is rich in relationships. It can be thought of as a connected web knowledge, a network in which the linking relstionships are as prominent as the discrete pieces of information. Then, [12] argued that static knowledge about facts, concepts, and principle that apply within a certain domain. Furthermore, understanding of the underlying structures of mathematics [13].This view provides confirmation that conceptual understanding is is a knowledge that contains many relationships, or network, where those relationships absorb individual facts and propositions so that all pieces of information related to multiple networks. Character conceptual understanding is a network of specific knowledge and skills contained therein. The elements of this network can be concepts, rules (algorithms, procedures, etc.), and even the problem (a problem solving can introduce a new concept or rule) is given in various forms of representation [14]. So the conceptual understanding in math is a set size on the quality and quantity of mathematical concepts that have been taught, which consists of an understanding of mathematical concepts, operations, and relationships.

\section{B. Procedural understanding}

Procedural knowledge refers to an understanding of specific mathematical procedures or rules; it represents knowledge of the sequence of actions (i.e., the step-by-step instructions) of what is needed to solve a problem [15]. Procedural knowledge involves attainment of facts, algorithms, and skills [16]. [11] states that One kind of procedural knowledge is a familiarity with the individual symbols of the system and with the syntactic conventions for acceptable configurations of symbols. The second kind of procedural knowledge consists of rules or procedures for solving mathematical problems. Many of the procedures that students possess probably are chains of prescriptions for manipulating symbols. Thus, procedural understanding is the use of certain rules right, algorithms or procedures in the form of relevant mathematical representation. This usually requires not only knowledge of objects that are used, but also knowledge about the format and syntax necessary for the system of representation.

This context shows that procedural knowledge is highly dependent on the ability of computing and the use of the procedure in the form of different representations. In contrast to the conceptual understanding, procedural knowledge does not require in-depth understanding of the concept being studied.

\section{Mathematical Investigation}

The underlying theoretical orientation mathematical investigation is a social constructivist theory. This theory is based on the belief that a child build knowledge and conceptual understanding through their own activities in order to build the mathematical knowledge. This theory saw mathematics as a social construction that is meaningful, where students are not considered as an object but as subject to continuous gain conduct active interaction in relation to others, so that the goal orientation constructivist for students is to take responsibility for their own learning, that is to become independent learners, to develop an integrated understanding of concepts, and problem posing and trying to answer important questions [17], which is the gist of the mathematical investigation.

[18] asserts that the investigation of mathematics can be viewed as a learning approach rather than just as a mere student activities. Through the study of mathematics by investigative approach, students learn and develop the knowledge and ability of mathematical processes through an integrated investigative activities in mathematics. Learning math like this will load the investigation activity, investigation task, investigation work or investigation process, also covers aspects of problem solving, filing problem, inductive reasoning and heuristic or mathematical thought process. Learning math with an investigative approach forms of indirect learning approaches (indirect approach), characterized by inductively. Increased student understanding of mathematical skills in the context of mathematical investigation caused by the investigation as an activity and as an investigation process. Explains that when students tried to open investigative tasks, they are engaged in mathematics called open investigative activities [10].

Mathematical investigation require additional skills in inquiry such as the assembly of information, description of previous knowledge, making the strategy, making interpretation, looking for patterns and related forms, explore the basic ideas, and considering whether it can be used in the new situation. Mathematical investigation is a reflection of the approach that allows students to engage, learn and remember their math skills [19].[20]gives the difference between investigative mathematics and problem solving. In solving the problem, students concentrate on a solution so that the focus is on obtaining the solution, while the investigation is 
characterized as an open-ended activities, where the focus is on the thought process of the search for solutions. Students are not expected to produce the correct answer but are required to explore the possibilities, make allegations, and to convince themselves and others of what they found. So the emphasis is exploration. All the characteristics that stand out from the investigation of mathematics has been cited by [21] in several studies, that is (1) the investigation is open investigative task with an open goal, open answer and divergent, (2) the investigation is also an a closed problem-solving task, (3) the investigation involves problem solving and problem posing, and (4) the investigation is a process of thinking.

\section{Aim and Research Questions}

In this study, researchers gave allegations regarding the relationship between variables studied, that is : (1) direct influence (main effect) of two factors of learning (mathematical investigation/MI and expository/ES) and prior knowledge of mathematics (PKM), to the conceptual and procedural understanding of students, and (2) the interaction between the learning factor and PKM to the conceptual and procedural understanding of students.

The problems shown in this study are: (1) Is the ability of conceptual and procedural understanding of students who studied with $M I$ better than students who study with ES?, (2) If the terms of $P K M$, is the ability of conceptual and procedural understanding of students studying by $M I$ approach is better than the students who study with $E S$ ?, and (3) Is there an interaction between learning factor $(M I$ and $E S)$ and prior knowledge of mathematics $(P K M)$ for increase the ability of conceptual and procedural understanding?

\section{RESEARCH METHOD}

\section{A. Participants}

The subjects were PGSD students enrolled in 2014 and is following the lecture "Mathematics Education II" in the first semester of academic year 2016/2017, which is divided into two classes. Before the treatment is given, the whole subject of research by PKM test and the results are used for decision making in determining control class and experimental class. Consideration of researchers is to know about the "homogeneity of variance". The test results showed that the statistics lavene value of 0.001 with a significance level of 0.971 . The level of significance, suggesting that both sets of data has a homogeneous variance for 0.971>0.05. Based on the above considerations, the chosen class control and experiment randomly. The result of this choice determines that the class A as the control class, and class B as a class experiment.

\section{B. Design}

Research design using Quasi-Experimental type design with pre-posttest design [22]. Based on this type, the researchers apply a pre-and posttest design, which is divided into two study groups: control group and the treatment group. Both groups were subjected to pretests as supporting material to perform the treatment, then do posttest to know the difference between the two groups.

\section{Instruments and Data Collection}

Data were collected through a process of pretest and posttest in both study groups (experimental and control). Pretest and posttest question contains a set of items in which there are indicators of critical thinking skills and mathematical reasoning. Number of items in pretest as many as four grains and post-test consists of 5 items, whole grains which of the measured variables of the study. Measurement of study variables using a score of $0-4$ in each category have been determined under the rubric and scoring techniques. Both these instruments do the testing process to test the validity and reliability of the instrument. Validity test using Pearson correlation test models. While the reliability of the instruments this study refers to internal consistency reliability with the test model used was Cronbach Alpha coefficients. Post-test instrument produces Pearson correlation values in the range of 0.701 to 0.781 with a Cronbach alpha value of 0.778 ; while pre-test produces Pearson correlation values that are in the range of 0.691 to 0.890 and the value of Cronbach alpha of 0.722 . These results that the instrument indicating the post-test and pre-test has validity and reliability that can be accounted for this study.

\section{Statistical analyses}

Descriptive analysis of data using descriptive statistical measures such as mean, standard deviation of, and curves. Then calculate the normalized gain on the score pre-test and post-test.

Test of homogeneity of variance using the model "Levene test". While the assumption of normality distribution of data using the Kolmogorov-Smirnov test model. ANOVA test was used to test the hypothesis, the F statistic by comparing two elements.

\section{RESULTS AND DISCUSSION}

\section{A. Distribution of gain value}

Distribution gain value were divided into 3 groups, ie high, medium and low. At the conceptual abilities in the experimental class, the highest percentage of $76.97 \%$ in the high group; whereas in the control class were in the medium group was at $38.18 \%$.

For procedural capabilities, the experimental class dominated by high group with a percentage of $75 \%$; while the control group, $60 \%$ were in the moderate group. This situation shows the difference in the percentage of the value of the gain obtained by the subjects in each class.

\section{B. The percentage of variable measurement indicators}

Comparison of the scores of indicators of research obtained research subjects can be seen in Table I.

These results illustrate that mathematics investigative approach provides movement score that much different in the two classes this study. 
TABLE I. COMPARISON SHOWS INDICATORS IN THE ANSWER SHEET

\begin{tabular}{|c|c|c|c|c|c|}
\hline \multirow{2}{*}{ Score } & \multirow{2}{*}{$\begin{array}{c}\text { Description of } \\
\text { the criteria }\end{array}$} & \multicolumn{2}{|c|}{ Conceptual } & \multicolumn{2}{c|}{ procedural } \\
\cline { 3 - 6 } & $\begin{array}{c}\text { Experime } \\
\text { nt (\%) }\end{array}$ & control(\%) & $\begin{array}{c}\text { Experim } \\
\text { ent (\%) }\end{array}$ & $\begin{array}{c}\text { control } \\
(\%)\end{array}$ \\
\hline 0 & $\begin{array}{c}\text { there are no } \\
\text { indicators that } \\
\text { appear }\end{array}$ & 1,79 & 1,82 & 5,36 & 27,27 \\
\hline 1 & $\begin{array}{c}\text { there is one } \\
\text { indicator that } \\
\text { appears }\end{array}$ & 1,79 & 13,63 & 2,68 & 21,82 \\
\hline 2 & $\begin{array}{c}\text { There are two } \\
\text { indicators that } \\
\text { appear }\end{array}$ & 16,96 & 20 & 7,14 & 6,36 \\
\hline 3 & $\begin{array}{c}\text { There are three } \\
\text { indicators that } \\
\text { appear }\end{array}$ & 4,46 & 14,55 & 12,50 & 20,00 \\
\hline 4 & $\begin{array}{c}\text { There are four } \\
\text { indicators that } \\
\text { appear }\end{array}$ & 75 & 50 & 72,32 & 24,55 \\
\hline
\end{tabular}

\section{Overview fluctuations of Conceptual abilities}

Overview fluctuations in the gain of a conceptual abilities can be seen in the following Fig 1 dan Fig 2.

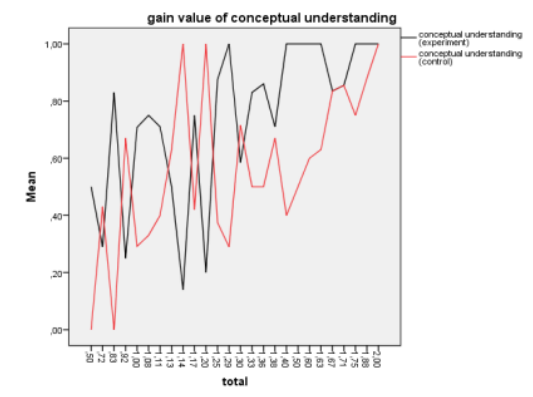

Fig. 1. Gain value of conceptual

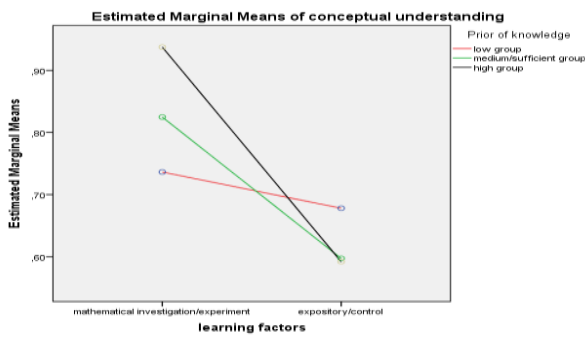

Fig. 2. Estimated marginal means of conceptual

The Fig 1 confirms that there is a gap between the value of the gain subject in class experimentation with the control class. This line graph provides a visualization that the ability of the conceptual of students in the experimental class moves on the numbers mean is higher than the mean in the control class movement. Despite a line "intersect", but overall it appears that the increase in the ability of conceptual abilities is higher in the experimental class compared with the control class. Then, profile plot above (fig 2), provide that information to the whole subject of research with different initial capabilities, the slope of the line is the same pattern, only large slope is different. Three lines that symbolize the three groups of early mathematical ability, always showing the condition in which the highest end point is always in the area of mathematical investigation and lowest end point in the region ekspository.

This indicates that the research subjects in the experimental class is able to provide enhanced capabilities conceptual abilities that is higher than the research subjects in the control class. Further interpretation, mathematical investigation can be given in different subjects in this study or in all students, because in this studyshowed no interaction between the types of approaches used and all kinds of early math abilities.

\section{Overview fluctuations of Procedural abilities}

Such as previous results, fluctuations in the gain of procedural abilities can be seen in Fig 3 and Fig 4.

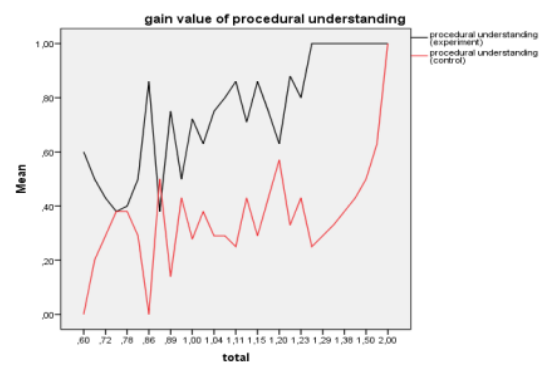

Fig. 3. Gain value of procedural

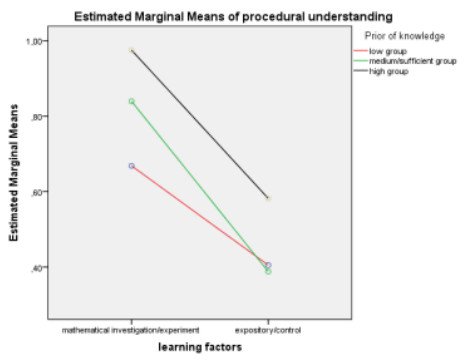

Fig. 4. Estimated marginal means of procedural

Fig. 3 provides information that movements gain value from procedural abilities, between the experimental class and control class, there is a fairly wide range. Fluctuations in the gain in the experimental class is always at the top of the control class, to the point of its movement is always higher than 0.5 points on the ordinate axis (mean). This suggests that increased abilitiesof procedural in the class of experiments over "sharp" when compared with the control class. Then the profile plot above (figure 4), provide the same information as before, namely that the whole subject of research with different initial capabilities, the slope of the line is the same pattern, only large slope is different. Three lines that symbolize the three groups of early mathematical ability, always showing the condition in which the highest end point is always in the area of mathematical investigation and lowest end point in the region expository.

This shows that through mathematical investigations in the classroom experimentation, an improved abilities of 
procedural better compared with classroom learning control. In addition, this condition indicates that there is no interaction between prior knowledge of mathematics with the learning factor to the increased procedural abilities of students.

\section{E. Results of hypothesis testing}

Analysis of variance were used after conducting a series of test requirements, namely the distribution normality test and homogeneity test. The test results showed that both tested the data gain, i.e the gain of the conceptual abilities and procedural abilities otherwise meet both of these assumptions.

Then the data hypothesis test using the test model "analysis of variance". The results of the analysis as follows.

TABLE II. SUMMARY RESULTS OF HYPOTHESIS TESTING

\begin{tabular}{|c|c|c|}
\hline $\begin{array}{c}\text { Statement alternative } \\
\text { hypothesis }\end{array}$ & $\begin{array}{c}\text { Univariate Analysis of } \\
\text { Variance }\end{array}$ & Conclusion \\
\hline $\begin{array}{l}\text { There is an increased of } \\
\text { conceptual abilities } \\
\text { the significance of students } \\
\text { who receive learning through } \\
\text { MI approach compared to the } \\
\text { ES approach }\end{array}$ & $\begin{array}{l}\text { a. } F=15,651 ; \text { the } \\
\text { corrected models and } \\
\text { PLK has sig. } 0.000< \\
0.05 \text {, with size-effect: } \\
12,6 \% \text {, }\end{array}$ & a. Accepted \\
\hline $\begin{array}{l}\text { There is interaction between } \\
\text { the teaching approaches used } \\
\text { (MI and ES) with PKM to } \\
\text { increase conceptual abilities } \\
\text { of students }\end{array}$ & $\begin{array}{l}\text { a. } \mathrm{F}=1,136 ; \text { the corrected } \\
\text { models and PLK has } \\
\text { sig. } 0.325>0.05\end{array}$ & a. Rejected \\
\hline $\begin{array}{l}\text { There is an increased of } \\
\text { procedural abilities } \\
\text { the significance of students } \\
\text { who receive learning through } \\
\text { MI approach compared to the } \\
\text { ES approach }\end{array}$ & $\begin{array}{l}\text { b. } F=109,435 ; \text { the } \\
\text { corrected models and } \\
\text { PLK has sig. } 0.000< \\
0.05 \text {, with size-effect: } \\
50,1 \% \text {, }\end{array}$ & b. Accepted \\
\hline $\begin{array}{l}\text { There is interaction between } \\
\text { the teaching approaches used } \\
\text { (MI and ES) with PKM to } \\
\text { increase procedural abilities } \\
\text { of students }\end{array}$ & $\begin{array}{l}\text { b. } \mathrm{F}=1,850 ; \text { the corrected } \\
\text { models and PLK has } \\
\text { sig. } 0.162>0.05\end{array}$ & b. Rejected \\
\hline
\end{tabular}

Another result is about interaction. The test results of interaction hypothesis suggests that the two variables studied were not affected by the interaction between the factors of learning and early math abilities possessed by the subjects. This means that the investigative approach mathematics can be applied to all students, regardless of their prior knowledge.

\section{F. Discussion and implications}

[23] classic piece on instrumental and relational understanding of mathematics, more recently referred to as procedural and conceptual abilities, drive author to think about ways of understanding mathematics for themselves and for their future students. The process of learning through mathematical investigations have some activity as a feature that can be used in developing a conceptual and procedural abilities of students. In this three-hour credit course, the equivalent of one hundred and fifty minutes of face-to-face in class, the students conduct "investigative activity" or "activity of thinking" that correspond to the material context of learning "math education II". There is a "class assignments investigation" and "homework investigation" given during learning in the classroom rather than focused on college textbook material. Students are given the opportunity that is wide enough to design, prepare, and resolve the problem. Help lecturers pursued minimal as possible. Students learn the power of geometry with to analyze characteristics of geometric shapes and make mathematical arguments about the geometric relationship, as well as to use visualization, spatial reasoning, and geometric modeling to solve problems. For example:

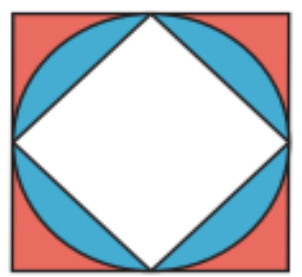

Based on the issue, expected in the development of conceptual and procedural abilities of students in identifying relevant mathematical concepts, procedures, or representation in such cases. Students seeking inter-relationship between the shapes that exist in the picture, then apply previously learned concepts (such as using the relationship between the area of the square and circle), making allegations and justify or validate the solution.

One of the reasons for the increased of conceptual and procedural abilities in the experimental class, which is viewed from the side which is owned by the abstract nature of mathematical material, particularly in the field of geometry. On this side and on certain conditions, requires a situation which gives students the opportunity to continue to reflect on (think) and make the conclusion of a mathematical formula that are being faced. Through investigative approach, where it contains aspects of investigative activities and aspects of the thinking process, requires students to understand the concepts related to the material being taught.[23] explains that understanding the conceptual/relational be achieved if students understand the underlying principles that make a particular formula or theorem and its relationship with other formulas or theorems. Improved conceptual understanding is driven by the training process in "doing practice questions of investigation" in the experimental class. Students are only given to points of concern and then, on their own solve the problem.

Context of the above, asserts that the investigation of mathematics is a process of thinking because it involves mental activity through the process of conjecturing, justifying, specializing and generaliing [10], resulting in the investigation there is a process of mathematical thinking. The thought process is going to develop high-level thinking skills of students depending on the given task. The higher the degree of difficulty of the task, the students will try to think more deeply to the completion of the task. This is in line with [24], saw the potential increase students conceptual understanding by teaching them to use problem-solving context. Formation of the conceptual context can also be done by applying mathematics is learned into a different context, so that the mathematical investigation into an approach that is good enough to be able to increase the ability of a student conceptual abilities. If students are able to apply mathematical 
concepts in as many contexts, their conceptual abilities of mathematics learning will be visible [25].

Another interesting result of this study is, the assertion that the value $P K M$ on the "low group", it turns out the ability of conceptual abilities does not provide a meaningful difference to the treatment given (fig 2) and the lack of interaction between the "factors of learning and $P K M$ " to increase the ability of conceptual understanding (fig 3 \& fig 4). Why increasing conceptual abilities not pursued by the majority of research subjects were capable of "low group" entry may be affected by several things. Problem and investigation task is challenging student so that the degree of difficulty of the task and the question above average. It would seem would seem to be "difficult" for the study subjects who began the process of solving the mathematical abilities of a low starting point. On this side, the role of teamwork strongly supports the increased understanding of them, although apparently not a significant difference between the experimental class and control class.

The impact is quite surprising is through a mathematical investigation can act as a catalyst for teachers. Mathematical investigation can become a "learning laboratory" on teachers who will prepare the materials of the investigation. That is, there is a "mixed results" will be achieved in this study, namely the achievement of learning goals for students and the occurrence of a process of increasing knowledge for teachers with the approach. Several studies provide evidence that teachers can strengthen their own mathematical understanding in the process of trying to make sense of students' work (e.g. [26]; [27]; [28]). Teachers can also strengthen their mathematical knowledge through planning and discussing mathematics lessons (e.g. [29]; [30]; [31]) and through interacting with students and colleagues in the course of implementing new instructional tasks or new curriculum materials [32].

Target population in this study relate to the students of the prospective elementary school teachers, the creation of an ideal condition is defined, is expected to move toward a tighter integration of the conceptual and procedural abilities of their mathematical skills. Developing this understanding is very important, because the empirical condition is quite alarming to the ability of primary school teachers, particularly in math. Through this study, at least provide a starting point to prepare for the establishment of a primary school teacher. Through continued collaboration of mathematics education experts, teachers and stakeholders in education, the increase in the conceptual and procedural abilities for mathematics teachers through investigation can continue to be integrated in a learning process.

\section{CONCLUSION}

The study gives some conclusions, that is (1) there is an increased ability to conceptual and procedural abilities which was significant at all the students who get teaching investigation of mathematics, (2) in terms of prior knowledge mathematics, high and medium group showed a significant increase in understanding, otherwise the low group gave different results and (3) there is no interaction between the learning undertaken factor (mathematical investigation and expository) with prior knowledge of mathematics to increase the ability of conceptual and procedural abilities.

\section{Acknowledgments}

This article is part of a doctoral dissertation research at Indonesia University of Education. We thank the Faculty of Teacher Training and Science Education, Halu Oleo University, which has provided assistance, so that the research carried out well.

\section{References}

[1] Baturo, A., \& Nason, R. (1996). Student teachers' subject matter knowledge within the domain of area measurement. Educational Studies in Mathematics, 31, 235-268

[2] Tierney, C., Boyd, C., \& Davis, G. (1990). Prospective primary teachers' conceptions of area. In G. Booker, P. Cobb, \& T. D. Mendecuti (Eds.), Proceedings of the 14th conference of the international group of the psychology of mathematics education (pp. 307-315). Mexico: IGPME.

[3] Chinnapan, M., \& Thomas, M. (2003). Teachers' function schemas and their role in modelling. Mathematics Education Research Journal, 15, $151-170$.

[4] Rizvi, N. F. (2004). Prospective teachers' knowledge about the concept of division. Bedford Park, South Australia: Flinders University of South Australia.

[5] Berenson, S., van der Valk, T., Oldham, E., Runesson, U., Queiroz Moreira, C., \& Broekman, H. (1997). An international study to investigate prospective teachers' content knowledge of the area concept. European Journal of Teacher Education, 20, 137-150.

[6] Brown, T., McNamara, O., Hanley, U., \& Jones, L. (1999). Primary student teachers' understanding of mathematics and its teaching. British Educational Research Journal, 25(3), 299-322.

[7] Byrnes, J. P., and Wasik, B. A. (1991). Role of conceptual knowledge in mathematical procedural learning. Developmental Psychology, 27(5), 777-786

[8] [8] Schneider, M., and Stern, E. (2012). The developmental relations between conceptual and procedural knowledge: a multi-method approach. Developmental Psychology, 46(1), 178-192

[9] National Council of Teachers of Mathematics. (2000). Principles and standards for school mathematics. <http://www.nctm.org/ standards/default.aspx $? \mathrm{id}=58>$.

[10] Yeo, J.B.W. dan Yeap, B.H. (2009). Mathematical Investigation : Task, Process and Activity. http://www citeseerx.ist.psu.edu/viewdoc/download;jsessionid

[11] Hiebert, J., and Lefevre, P. (1986). Conceptual and procedural knowledge in mathematics: an introductory analysis. In J. Hiebert (Ed.), Conceptual and procedural knowledge: The case of mathematics (pp. 127). Hillsdale, NJ: Erlbaum

[12] De Jong, T., and Ferguson-Hessler, M. G. M. (1996). Types and qualities of knowledge. Educational Psychologist, 31(2), 105-113

[13] Robinson, K. M., and Dube, A. K. (2009). A microgenetic study of the multiplication and division inversion concept. Canadian Journal of Experimental Psychology, 63(3), 193-200

[14] [14] Lauritzen, P. (2012). Conceptual and Procedural Knowledge of Mathematical Functions. (Dissertation). Joensuu: University of Eastern Finland. Publications of the University of Eastern Finland Dissertations in Education, Humanities, and Theology

[15] Rittle-Johnson, B., and Alibali, M. W. (1999). Conceptual and procedural knowledge of mathematics: Does one lead to the other? Journal of Educational Psychology, 91, 175-189

[16] Ross, A and Willson, V. (2012). The Effects of Representations, Constructivist Approaches, and Engagement on Middle School Students' Algebraic Procedure and Conceptual Understanding. School Science and Mathematics, 112 (2), 117-128 
[17] Tobin, K. and Tippins, D. (1993). Constructivism as a referent for teaching and learning. In K. Tobin (Ed.), The practice of constructivism in science education (or TPCSE, pp. 3-21). Hillsdale, NJ: Erlbaum

[18] Copes, L. (2008). Discovering Geometry : An Investigative Approach. Emeryville : Key Curriculum Press.

[19] Sangster, Margaret (2012). The rise and fall of an investigative approach to mathematics in primary education. In. Smith, C. , ed. Proceedings of the British Society for Research into Learning Mathematics, 32(1), 4346

[20] Grimison, L. and Dawe, L. (2000). Report Supporting Investigations for the Advanced and Intermediate Courses of the NSW Mathematics Years 9-10 Syllabus. Copyright 2000 Board of Studies NSW. The University of New South Wales

[21] Yeo, J. B. W. dan Yeap, B.H. (2010). Characterising the Cognitive Processes in Mathematical Investigation. http://www.cimt.plymouth.ac.uk/journal/jbwyeo

[22] Creswell, J.W. (2012). Educational Research. Fourth Edition. Edwards Brothers. Inc. Boston

[23] Skemp, R. R. (1976). Relational understanding and instrumental understanding. Mathematics Teaching, 77, 20-26

[24] Yager, R. (1991). The constructivist learning model, towards real reform in science education. The Science Teacher, 58 (6), 52-57

[25] Hiebert, J., and Carpenter, T. (1992). Learning and teaching with understanding. In D. Grouws (Ed.), Handbook of research on mathematics research and teaching(pp. 65-100). New York, NY: MacMillan

[26] Confrey, J., Castro, J., and Wilhelm, J. (2000). Implementation research as a means to link systemic reform and applied psychology in mathematics education. Educational Psychologist, 35(3), 179-19

[27] Jaberg, P., Lubinski, C., and Yazujian, T. (2002). One teacher's journey to change her mathematics teaching. Mathematics Teacher Education and Development, 4, 3-14

[28] Jacobs, V. R., Franke, M. L., Carpenter, T. P., Levi, L., and Battey, D. (2007). Professional development focused on children's algebraic reasoning in elementary school. Journal for Research in Mathematics Education, 38(3), 258-288

[29] Borko, H., Jacobs, J., Eiteljorg, E., and Pittman, M. E. (2008). Video as a tool for fostering productive discussions in mathematics professional development. Teaching and Teacher Education, 24, 417-436

[30] [30] Fernandez, C. (2005). Lesson study: A means for elementary teachers to develop the knowledge of mathematics needed for reformminded teaching? Mathematical Thinking and Learning, 7(4), 265-289.

[31] Lin, P. (2002). On enhancing teachers' knowledge by constructing cases in classrooms. Journal of Mathematics Teacher Education, 5(4), 317 349 .

[32] Doerr, H. M., and English, L. D. (2006). Middle grade teachers' learning through students' engagement with modeling tasks. Journal of Mathematics Teacher Education, 9(1), 5-32. 